\title{
El pensamiento estético de Nicolás de Cusa en el espectro de la luz renacentista
}

\author{
Evgenia Kuzmina*
}

\begin{abstract}
Resumen: Nicolás de Cusa representa una figura clave en el pensamiento estético y filosófico del Renacimiento, revelando las principales tendencias del mismo en su metafísica. Anticipó algunos de los rasgos de la época moderna, pero sin rechazar por completo el intelectualismo y el universalismo medievales. La concepción filosófica de Nicolás de Cusa contiene intrínsecamente una profunda reflexión estética. El cardenal alemán muestra un gran interés por los problemas de la creación, la mímesis, la percepción visual y la variedad. La característica fundamental de su planteamiento es la utilización de metáforas vinculadas a las artes plásticas, ciencias ópticas y matemáticas. La estética de Nicolás de Cusa y la práctica artística y teórica del Renacimiento son componentes de un paradigma común y, aunque los objetivos de la filosofía mística y el arte son diferentes, los medios para sus logros pueden ser similares y mutuamente esclarecedores.
\end{abstract}

Palabras clave: Mímesis, creación, imagen, espejo, arte.

\begin{abstract}
Nicholas de Cusa is a key figure in Renaissance aesthetic and philosophic thinking, and unveiled its fundamental tendencies in his metaphysics. He anticipates some of the characteristics of the modern era, but without completely rejecting medieval intellectualism and universalism. The philosophical conception of Nicholas de Cusa intrinsically includes profound aesthetic reflection. The German cardinal demonstrates great interest in the problems of mimesis, creation, visual perception and variety. A fundamental characteristic of his approach is the use of metaphors related to the plastic arts, the optical sciences and mathematics. The aesthetics of Nicholas de Cusa and the artistic practice and theory of the Renaissance are two components of a common paradigm, and while the objectives of mystic theology and art are different, the means to reach their ends can be similar and mutually enlightening.
\end{abstract}

Key words: Mimesis, creation, image, mirror, art.

Résumé: Nicolas de Cusa constitue la figure-clé de la pensée esthétique et philosophique de la Renaissance car il révèle les principales tendances de cette dernière dans le cadre de sa métaphysique. Il a anticipé certains des traits de l'époque moderne, mais sans refuser entièrement l'intellectualisme et l'universalisme des temps médiévaux. La conception philosophique de Nicolas de Cusa contient intrinsèquement une profonde réflexion esthétique. Le cardinal allemand fait montre d'un grand intérêt pour les problèmes de la création, de la mimésis, de la perception visuelle et de la variété. La caractéristique fondamentale de la proposition de Cusa est l'utilisation des métaphores liées aux arts plastiques, aux sciences optiques et aux mathématiques. L'esthétique de Nicolas de Cusa et la pratique artistique et théorique de la Renaissance sont les composants d'un paradigme commun et, bien que les objectifs de la philosophie mystique et de l'art soient différents, les moyens pour les atteindre peuvent être similaires et s'éclairer mutuellement.

Mots-clés: Mimésis, Création, Image, Miroir, Art.

* Personal investigador en formación, Departamento Historia del Arte, Universidad de Navarra, España. (ekuzmina@alumni.unav.es)

Recibido: 2010 - 04 - 16

Aprobado: 2010 - 05 - 17 


\section{Introducción}

Nicolás de Cusa es una figura clave del pensamiento estético y filosófico del Renacimiento; sus ideas se caracterizan por una profundidad y complejidad mucho mayores que las de gran parte de las corrientes intelectuales de la época ${ }^{1}$. Anticipó, sin duda alguna, algunos de los rasgos de la época moderna, pero sin rechazar por completo el intelectualismo y el universalismo medievales. Cabe señalar que a los ojos de sus contemporáneos, Nicolás de Cusa fue un gran conocedor del medievo. Así es presentado por el obispo de Aleria, Juan Andrea, en su necrología de 1469 (el primer documento donde se utiliza la expresión Edad Media ${ }^{2}$ ), el autor de una de las crónicas de la historia internacional, Hartman Schedel, en 1493 y el editor parisino de Nicolás, Faber Stapulensis, en 1514. Nicolás de Cusa sintetizó en su filosofía las tradiciones de la mística alemana (empezando por Eckhart), la escolástica medieval (sobre todo, Alberto Magno, Tomás de Aquino y Raimundo Lull ${ }^{3}$ ) y, finalmente, lo que sirvió como el principio activo de su pensamiento, el naciente humanismo italiano. Aunque la mística de Nicolás de Cusa era manifiesta, su escolástica perdió su forma medieval y se pre-

1 Sobre la relación de Nicolás de Cusa y humanismo europeo, puede consultarse: E. Cassirer, Individuo y cosmos en la filosofía del Renacimiento, traducción de A. Bixio, Buenos Aires, Emecé, 1951; P. Kristeller "Humanismus", en Ch. B. Schmitt (ed.), The Cambrige History of Renaissance Philosophy, Cambridge, Cambridge University Press, 1988, pp. 111-137; M. Seidlmayer, "Nikolaus von Cues und der Humanismus", en J. Koch (ed.), Humanismus, Mystik und Kunst in der Welt des Mittelalters, Brill, Leiden-Koln, 1953, pp. 1-39; K. Flasch, "Nikolaus von Kues und Pico della Mirandola", MFCG, 14 (1980), pp. 113-120; P. Gamberoni, "Cusanus und der italienische Humanismus", BijdragenTijdschrift voor Filosofie en Theologie, 25 (1964), pp. 398-417; P. M. Watts, "Renaissance Humanism", en P. M. Watts (ed.), Introducing Nicholas of Cusa: a Guide to a Renaissance Man, New York, Paulist Press, 2004 pp. 169-205. En el contexto estético puede verse sobre todo G. Pochat, Historia de la estética y la teoría del arte, traducción de J. Ch. Mielke, Madrid, Akal, 2008, pp. 210-215; W. Tatarkiewicz, Historia de la estética, traducción de D. Rurzyka, Madrid, Akal, 1991, pp. 79-85. E. Hempel, Nikolaus von Kues in seinen Beziehungen zur bildenden Kunst, Berlin, Akademie-Verlag, 1953; G. Santinello, Il pensiero di Nicolò Cusano nella sua prospettiva estetica, Padova, Liviana, 1958.

2 Cassirer, Individuo..., ob. cit., p. 53.

3 Ibídem, p. 54. sentó solo mediante el universalismo, la sistematización y la claridad lógica, mientras que su humanismo carecía de pretensiones de psicologismo y retórica.

Las ideas filosóficas de Nicolás de Cusa influyen de una manera inmediata en su planteamiento estético, que, sin poseer un carácter sistemático, tiene una gran relevancia para la historia de la cultura.

Nos centraremos fundamentalmente en los aspectos de la estética de Cusa que se refieren a las nociones de creación, mímesis, imagen y espejo.

El método que vamos a emplear a la hora de analizar la concepción estética de Cusa será ver la aportación del filósofo alemán en el contexto de las manifestaciones teóricas y artísticas de su tiempo.

\section{La imitación y la creación}

El tema del mundo de la naturaleza y del arte y su interacción ${ }^{4}$, así como la concepción del arte en sí, constituye un problema clave para entender el planteamiento estético de Nicolás de Cusa y es fundamental para nuestro estudio, puesto que buscamos analizar la relación que existe entre la concepción de Nicolás de Cusa y el arte.

Su estética en este aspecto, como en otros muchos casos, se encuentra en la encrucijada de lo tradicional y lo moderno. Su concepción es conservadora porque cabe dentro de los marcos del platonismo ${ }^{5}$. Sin embargo, las ideas que toma de Platón se orientan no tanto hacia la metafísica

4 Sobre el tema de la mímesis y la creación artística en Cusa, véase J. M. André, "La dimensión simbólica del arte en Nicolás de Cusa", Anuario filosófico, 28 (1995), pp. 556-569.

5 Cfr. Tatarkiewicz, Historia de..., ob. cit., p. 80. 
idealista, como hacia la teoría apriorística de la cognición y la teoría espiritualista de las actividades intelectuales. De tal manera que su pensamiento, partiendo de la concepción tradicional, hace una contribuición propia a la teoría artística que se relaciona con las tendencias renacentistas (como veremos más adelante) y que va a tener también un desarrollo posterior.

Las artes humanas son las manifestaciones del intelecto humano ${ }^{6}$, o sea, éstas son libres y autónomas. Las artes son ejemplos de la expresión del magisterio de la mente creativa y como tales deben reflejar la individualidad del artista mediante su estilo personal ${ }^{7}$. El origen y el comienzo del arte reside en una visión creativa de la que nacen en la mente las formas de las cosas y las adecuadas proporciones. Así, el intelecto en el acto de percepción visual (es decir, la visión no es pasiva sino activa) adquiere un protagonismo en el proceso de la creación artística ${ }^{8}$.

La mente lleva en sí la idea de lo bello que se materializa en los objetos bellos que crea el ser humano 9 . Esta primacía de la idea sobre la realización en una obra de arte, esta ideificación de la imagen, es característica de la cultura renacentista $^{10}$.

En el tratado De Ludo Globi ${ }^{11}$ encontramos la exposición de la teoría sobre la productividad de la mente que es capaz de crear ficciones y concebir las ideas y la consiguiente realización de estas ideas en el material. Aunque se otorga más protagonismo a la concepción de la obra de arte, El Cusano admite que el proceso de creación no es exclusivamente intelectual, puesto que requiere una actividad física, manual, para la materialización de las ideas en una forma concreta, por lo cual, la creación es un acto intelectual-productivo ${ }^{12}$.

10 Sobre el concepto de la Idea en el Renacimiento véase E. Panofsky, Idea. Contribución a la historia de la teoría del arte, traducción de M. T. Pumarega, Madrid, Cátedra, 1977, pp. 45-67.

12 G.. Santinello, "L'uomo 'ad imaginem et similitudinem' nel Cusano", Doctor Seraphicus, 37(1990), p.65. Santinello analiza el problema de la de
}

Sin embargo, los resultados de esta actividad no pueden alcanzar al ideal que crea la mente:

Por ejemplo, el hombre posee el arte mecáni$\mathrm{co}, \mathrm{y}$ tiene en su concepto mental las figuras de este arte con más verdad que las que son configurables fuera de él, lo mismo que una casa, que es hecha por el arte, posee una figura más verdadera en la mente que en las maderas. La figura que se realiza en las maderas es una figura mental, idea o ejemplar; y dígase lo mismo de todas las demás cosas semejantes ${ }^{13}$.

Así como todo lo existente en el mundo terrenal es la similitud ${ }^{14}$, la explicación, de la verdad suprema e infinita y, como tal, nunca puede igualarse a $\operatorname{Dios}^{15}$, de la misma manera las creaciones humanas, que no son sino similitudes del intelecto humano, no pueden llegar a la perfección de la idea que guía la mente. A pesar del reconocimiento, por parte de Cusa, de una cierta autonomía de la creación artística del hombre, ésta debe someterse a las leyes objetivas de la naturaleza de la materia que necesita el artista para su actividad, mientras que Dios no tiene limitaciones de ningún tipo ${ }^{16}$.

El hombre imita a Dios mediante sus creaciones conceptulaes y artísticas, y lo hace a través de la imitación de la naturaleza ${ }^{17}$, la cual, vista dentro de su fuente, es el arte, el fruto del acto divino, conscientemente dirigido, que es la creación artística ${ }^{18}$ :

creación en la estética de Nicolás de Cusa desde el punto de vista de dos conceptos tan opuestos como pueden ser el acto contemplativo y el acto productivo.

$13 D B, 56$, p. 44.

14 Sobre el concepto de similitud en Nicolás de Cusa, véase el artículo de Santinello, citado más arriba; M. Alvarez -Gómez, "Adecuación e identidad. Sobre la idea de verdad en Santo Tomás y Nicolás de Cusa", Anales de la cátedra Francisco Suárez, 4 (1964), pp. 49-50; Á. L. González, "Introduccción", en Nicolás de Cusa, El Berilo, introducción, traducción y notas de Á. L. González, Cuadernos de Anuario Filosófico, № 200, Pamplona, Servicio de Publicaciones de la Universidad de Navarra, 2007, pp. 13-16; H. Schwaetzer, "Viva similitudo", en H. Schwaetzer (ed.), Nicolaus Cusanus: Perspectiven seiner Geistphilosophie, Regensburg, Roderer, 2003, pp. 79-95.

15 Cfr. DI, L.II, cap. I, pp. 104-105.

16 Cfr. Santinello, Il pensiero..., ob. cit., p. 253.

17 Cfr. Ibídem, pp. 252-261.

18 Esta concepción aparece por vez primera en Santo Tomás de Aquino, donde el arte es entendido como creación, no una mera reproducción mediante la imitación de las leyes formativas de la naturaleza. Debo esta sugerencia a la profesora Paula Lizarraga. Un comentario sobre 
Se piensa fácilmente que la inteligencia participa del arte, en la medida en que emana de la razón divina, pero, puesto que engendra por sí el arte, vemos que es la naturaleza. El arte es una cierta imitación de la naturaleza, y es evidente que unas cosas sensibles son naturales, otras son artificiales. Pero no es posible que las cosas sensibles naturales se encuentren privadas del arte, lo mismo que las sensibles artificiales no pueden estar privadas de la naturaleza ${ }^{19}$.

Santinello en su ensayo sobre el pensamiento estético de Cusa indica: "El mundo del hombre y el mundo de la naturaleza, el procedimiento espontáneo de la naturaleza y el procedimiento reflexivo del arte humano se complementan y no se contradicen" ${ }^{20}$.

Así, en el tratado De Coniecturis vemos cómo se afirma que nada puede darse que sólo sea naturaleza o arte: pues todo participa a su manera en ambas ${ }^{21}$, de tal manera que el mundo aparece como un producto común del arte humano y de la naturaleza. La naturaleza crea materia, mientras que el hombre, a su vez, crea cosas que no existen en la naturaleza, es decir, el hombre da forma a la materia.

La complementación y la profundización de los procesos artísticos se convierten en un camino para comprender la propia naturaleza:

(...) en la medida en que el arte imita a la naturaleza, llegamos a comprender las fuerzas de la naturaleza a partir de las cosas que sutilmente descubrimos en el arte ${ }^{22}$.

En este punto, nos gustaría profundizar más en la definición del concepto de la imitación o, dicho de otro modo, de la mímesis en la teoría estética de Nicolás de Cusa. En consecuencia, cabe preguntarse: ¿Qué es lo que

\footnotetext{
el concepto de la creación de Tomás de Aquino y su relación con la estética renacentista puede verse en R. Betrán, Leon Battista Alberti y la teoría de la creación artística en el Renacimiento, Zaragoza, Delegación en Zaragoza del Colegio Oficial de Arquitectos de Aragón, 1992, pp. 50-60.

19 DC, L. II, cap. XII, 131, p. 219.

20 Santinello, Il pensiero..., ob. cit., p. 254.

21 DC, L. II, cap. XII, p. 219.

$22 L G_{\prime \prime}, 7$, p. 253
}

entiende Nicolás de Cusa bajo el término de "imitación de la naturaleza"? ¿Simplemente una imitación de los productos de la misma?

Como hemos visto, el problema de la mímesis tiene en las especulaciones de Cusa un sentido más profundo. La mente se reconoce como creadora de las similitudes de su propio intelecto: las entidades racionales y formas artificiales que constituye la segunda creación de la mente como segundo dios ${ }^{23}$. Este reconocimiento consiste en que el intelecto se hace consciente de la existencia de un cierto grado de mímesis, cuando el lugar del ejemplar está ocupado no por los objetos naturales como tales, sino que se define por el acto creativo proporcional como imitador del acto creador divino que se manifiesta en la naturaleza misma ${ }^{24}$. En efecto, lo que se pretende imitar no es meramente una mimética reproducción del mundo real, sino el acto natural de la formación mediante el cual el hombre puede acercarse al arte divino:

Todo arte finito procede del arte infinito. $\mathrm{Y}$ así será necesario que el arte infinito sea el ejemplar, el principio, el medio, el fin, la medida, la verdad, la precisión y la perfección de todas las $\operatorname{artes}^{25}$.

Las artes humanas son imágenes del intelecto humano que permanece inmultiplicable y que puede revelarse solo en la variedad multiplicable de sus creaciones, en la variedad de las formas artísticas:

(...) el intelecto humano, aun permaneciendo uno e indivisible en sí, se manifiesta visiblemente de modo diferente en sus diversas artes y en los diversos productos de las artes ${ }^{26}$.

De tal manera que la variedad es algo positivo y negativo a la vez. Negativo en cuanto el mundo humano es una similitud de la imagen del Dios y como tal no es la unidad sino la diversidad ${ }^{27}$, por eso las artes humanas son

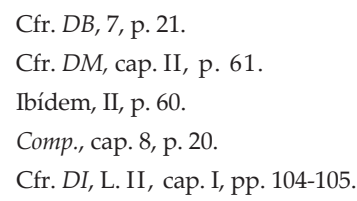


conjeturales o accidentales. Pero la variedad es también un logro del artista, puesto que la obra creada por el hombre llega a ser el arte en la medida en que se diferencia de la naturaleza, porque una obra de arte tiene que ser distinta de la de la naturaleza ${ }^{28}$.

Este planteamiento parece trazar una línea entre la concepción medieval que considera el arte humano como una actividad pasiva y una concepción moderna que vincula el arte con el acto creativo.

\section{El problema de la mímesis y la creación en el Renacimiento}

A partir del siglo XV el concepto de imitación se convierte en un aspecto básico de la teoría de las artes visuales ${ }^{29}$, siendo pioneros Lorenzo Ghiberti, Leon Battista Alberti y Leonardo da Vinci. Así, Ghiberti en sus Comentarios se preocupa por el problema del conocimiento de las leyes de la naturaleza a través del arte ${ }^{30}$. Alberti propone una doble concepción de la creación artística y la mímesis basada en la relación entre la naturaleza y el arte. La creación artística es una imitación de las leyes que rigen la naturaleza y no meramente de su aspecto físico. Por otro lado, cabe señalar el concepto de la Idea en la creación que eleva el arte por encima de la mera imitación de las cosas, con la experiencia directa de la naturaleza ${ }^{31}$. Para Leonardo la mímesis se presenta como la fidelidad a la naturaleza en la que mejor puede apreciarse la creatividad del artista que transforma su mente a semejanza de la ciencia divina. Por otro lado, Leonardo sostenía que el artista no es un espejo, porque no sólo refleja las cosas sino que también las conoce ${ }^{32}$.

\footnotetext{
28 Cfr. Santinello, Il pensiero..., ob. cit., p. 255.

29 Sobre el problema de la mímesis en el Renacimiento véase W. Tatakiewicz, Historia de seis ideas: arte, belleza, forma, creatividad, mímesis, experiencia estética, traducción de F. Rodríguez Martín, Madrid, Alianza, 2008, pp. 301-347; R. W. Lee, Ut pictura poesis: La teoría humanística de la pintura, traducción de C. Luca de Tena, Madrid, Cátedra, 1982, pp. 23-35; Panofsky, Idea...ob. cit., pp. 46-47.

30 Cfr. Pochat, Historia..., ob. cit., p. 216.

31 Cfr. Tatarkiewicz, Historia..., ob. cit., pp. 107-108.

32 Ibídem, pp. 162-163.
}

El objeto de la imitación no es la materia empírica como tal, sino el proceso creativo de la naturaleza concebida como una substancia viva que posee una energía autónoma generada por la razón divina. De ahí que la naturaleza se reflejara en este mismo arte vivo, carente de la pasividad, convirtiéndose de esta manera ella misma en la imagen del Dios.

La práctica artística, es decir, las artes humanas, en el proceso de la competición con la naturaleza-artista, no simplemente la imitaban, sino trataban de ver en ella a Dios.

La contemplación amorosa, la introspección en la naturaleza, se entendía como la profunda cognición de la misma. El artista se preocupaba por el problema de plasmación en el material de los resultados de la cognición de lo divino en la naturaleza mediante una convincente recreación del mundo real en las formas tridimensionales.

Así, el ilusionismo que se alaba y que se busca en las artes visuales servía como puente para penetrar mediante la creación artística a nivel transcendental en el enigma del proceso productivo de la naturaleza misma. De ahí que el naturalismo del arte renacentista no tanto reproduce, como conoce mediante la realización de una obra de arte. En este proceso de cognición el hombre ayuda a la naturaleza a revelarse, formando con ella un espacio común.

La imitación de la naturaleza divina se convierte en una experiencia intelectual que toma como punto de partida la imaginación. Así, lo que se pretende imitar no son los productos o las imágenes, sino los planes e ideas y es el deber del artista acercarse en el proceso formativo al ejemplar mental ${ }^{33}$.

Otra categoría en la que nos gustaría detenernos aquí es la de la varietá. La categoría de la variedad es intrínseca en la cultura del Renacimiento. La variedad se revela como la visión del mundo y se manifiesta mediante las enu-

\footnotetext{
33 Sobre la imitación en las artes plásticas, M. Sokolov, El misterio de la vecinidad. Hacia la metamorfología del arte en el Renacimiento, Moscú, Progress, 1999, pp. 55-119; M. Baxandal, Painting and Experience in Fifteenth Century Italy: a Primer in the Social History of Pictorial Style, Oxford, Oxford University Press, 1988, pp. 118-119.
} 
meraciones, como un método para organizar el universo que se presenta, sobre todo, ante los ojos. Lo genérico es entendido en muchos casos como un todo. Como consecuencia de este fenómeno, sigue una serie de infinitas variaciones de lo singular que se detiene en cada Todo, en cada manifestación particular e individual, de tal manera que un Todo se convierte, por este orden, en el centro y la actualización del Todo. Esta diversidad conceptual hace su presencia, por ejemplo, en la imagen de la arboleda pastoril que traza Sannazaro ${ }^{34}$, en la concepción de la belleza del mundo como variedad que presentan Manett $^{35}$, Landino ${ }^{36}$ o Leonardo da Vinci, entre otros $^{37}$. Aquí interesa, sobre todo, ver cómo se revela esta categoría en la obra de Leon Battista Alberti, puesto que las relaciones que tuvo con El Cusano fueron notables.

Alberti afirma en su tratado Della pittura que el artista, si quiere ser alabado, debe proporcionar el placer y deleite con su obra "y lo primero que da placer en la historia es la abundancia y la variedad"38. Variedad como una característica esencial de la historia que deleita al espectador y que es propia de la naturaleza universal, Dios también creó el mundo de la variedad, de ahí que mediante la representación de la variedad en su cuadro, el pintor imita el acto productivo de Dios. Así, en los cuadros renacentistas, sobre todo, en el Quattrocento, se aprecia la gran cantidad de elementos anecdóticos o idílicos, la variedad de los personajes representados y una proliferación en la caracterización de los ambientes y los personajes ${ }^{39}$. Sin embargo,

34 Cfr. I.Sannazaro, La Arcadia, traducción de J. M. Mesanza, Madrid, Editora Nacional, 1982, pp. 31-32.

35 Cfr. G. Manetti, “De dignitate et excelentia hominis”, en E. Garin (ed.) Prosatori latini de Quattrocento, Milano, R. Riccciardi, 1952, pp. 122-123.

36 Véase el proemio de Landino a su traducción del latín al italiano de la Historia Natural de Plinio el Viejo y publicada en C. Landino, Scritti critici e teorici, R. Cardini (ed.), vol. 1, Roma, Bulzoni, 1974, pp. 81-82.

37 Para el análisis de la categoría varietá en la cultura del Renacimiento, cfr. L. Batkin, Leonardo da Vinci y las particularidades del pensamiento artístico en el Renacimiento, Moscú, Iskusstvo, 1990.

38 L. B., Alberti y Leonardo da Vinci, El tratado de la pintura y los tres libros que sobre el mismo arte escribió León Bautista Alberti, traducción de D. A. Rejón de Silva, Valencia, Librerías París-Valencia, 1989, p. 236; Sobre la categoría de varietá en Alberti, véase M. Gosebruch, "Varieta bei Leon Battista Alberti und der wissenschaftliche Renaissancebegriff", Zeitschrift für Kunstgeschichte, Bd20, Heft3 (1957), pp. 229-238.

39 Cfr. H. Wölfflin, El arte clásico: una introducción al Renacimiento italiano, traducción de A. Dieterich, Madrid, Alianza, 1985, pp. 237-261. para poder apreciar la belleza del universo creado por el arte de la pintura, el espectador tiene que detenerse en la contemplación de cada objeto representado. Así, un paisaje renacentista que refleja el macrocosmos expresado por un punto de vista lejano no puede ser apreciado adecuadamente sin esta pausada contemplación, puesto que el paisaje renacentista siempre está composicionalmente desenfocado, repartido en unas partes desiguales y equivalentes y es reconstruido solo gracias al movimiento del ojo.

Para ver cómo esta categoría se une a las de creación y mímesis en la percepción visual en la época renacentista, nos centraremos en un ejemplo relacionado con el arte flamenco.

El talento de los pintores se valora a partir de la capacidad del artista para introducir la variedad en sus cuadros. Así, el humanista italiano Cyriacus de Ancona describe el cuadro perdido de Rogier van der Weyden en el que se maravilla por el divino talento del artista para plasmar en su composición los variados objetos del mundo que parecen vivos, mediante lo cual el pintor se equipara en su acto productivo a la naturaleza ${ }^{40}$.

En este breve recorrido sobre la historia del concepto de mímesis en la teoría artística del Renacimiento pudimos ver que las ideas de Nicolás de Cusa sobre la complementariedad de las artes del hombre y de la naturaleza y su concepción como explicaciones, similitudes del ejemplar divino, la primacía de la idea en el proceso creativo, la potencia imaginativa de la mente, la variedad y, finalmente, la mímesis como acto creativo que pretende imitar no los artefactos de la naturaleza, sino el proceso productivo de la misma, se corresponden con el pensamiento estético renacentista.

40 “Yo llamaría este arte más divino que humano. Aquí puedes ver (...) sobre todo las vestimentas, los manteles de los soldados, los vestidos confeccionados prodigiosamente decoradas con el purpuro y oro, los prados verdeantes y flores y árboles y colinas frondosas y sombrías y pórticos y vestíbulos adornados, con oro que parece oro real, y perlas y piedras preciosas y todo lo demás que puede imaginar creado no por las manos humano del artificie sino por la propia natnaraleza...",comentario de Cyracus de Ancona, citado por W. Stechow, Northern Renaissance Art, 1400-1600: Sources and Documents, Evanston, Ill., Northwestern University Press, 1999, p. 9. 


\section{La imagen y el espejo}

Una mirada global sobre la obra de Nicolás de Cusa permite ver las múltiples perspectivas de la utilización de las metáforas de la imagen y el espejo por parte de este autor. Tomadas del concepto tradicional de la expresión de San $\mathrm{Pa}-$ blo como per speculum in aenigmate (1 Cor. 13, 12) y en el Génesis ${ }^{41}$, estas metáforas hacen su presencia principalmente en la didáctica religiosa de Cusa, pero también en sus originales metáforas de la filosofía del espíritu que se basan en la imagen de Dios.

El concepto del espejo que aparece en el epistolario de San Pablo, que acabamos de señalar, es usado por Nicolás de Cusa en una predicación de 1456 para resaltar el papel de Cristo: Jesús aquí aparece como una verdadera imagen de Dios y el espejo sin mancha, el hombre está creado a imagen de Dios. Esta metáfora de la imagen se vincula al término de la similitud del arte pictórico a Dios, que tras una mirada en el espejo, ha hecho su autorretrato sobre la base de esta perfecta reflexión, formado por distintos elementos conectados entre sí. Así como el reflejo en el espejo es primario, no hecho por las manos, de la misma manera la representación en el retrato, según la imagen del espejo, es una imagen secundaria, creada por los seres humanos que son capaces de crear solo una similitud, pero no pueden llegar a una representación exacta del ejemplar.

Similitud es aquí, como en otras metáforas, un definido punto de argumentación. La antropología de Cusa representa una especial forma dinámica con respecto a la analogía conceptual tradicional que se ocupa también de una similitud $^{42}$ que no es similar. Aunque las creaciones

41 En el Génesis 1, 26 el hombre se presenta como una similitud de Dios. En la antropología teológica el Dios creador se asocia metafóricamente con el artista que representa una figura o pinta un retrato. Véase R. Preimesberger, "Der Verfasser der Priesterschrift: ... nach unserem Bild, uns ähnlich (6 Jhdt.v. Chr.)", en R. Preimesberger y otros (eds.), Porträt (Geschichte der klassischen Bildgattungen in Quellentexten und Kommentaren, 2), Berlin, Reimer,1999, pp.70-75.

42 Sobre la historia del concepto véase D. Jansen, Similitudo. Untersuchungen zur den Bildnissen Jan Van Eycks, Dissertationen zur Kunstgeschichte 28, Köln/Wien,1988, pp. 35-40; R. Preimesberger, “Caius Secindus d. Ä.: Ähnlichkeit (77n.Chr.)”, en Preimesberger, Porträt, ob. cit., pp. 127-133. forman parte del Creador a través de su similitud como reflejo de ese Creador, sin embargo, ningún reflejo de este prototipo es tan parecido a su ejemplar que no pueda ser infinitamente más similar.

De Cusa, en La Docta Ignorancia plantea un dinámico concepto de la similitud a través de la metáfora del espejo. La similitud o carencia de la misma, creada por los hombres a partir de la imagen de Dios se entiende en términos de la voluntad que posee el hombre para acercarse al ejemplar. La similitud para el filósofo alemán aquí no es un estado incambiable, pues aunque Dios puede revelarse, verse a través de las creaturas casi como en un espejo o un enigma, el grado de la similitud depende del acto productivo y diferenciador realizado por el hombre ${ }^{43}$.

Quizá, una metáfora más rica del espejo y de la imagen se desarrolla en el tratado de $\mathrm{La}$ Visión de Dios. En este escrito se pretende demostrar un camino para explicar las verdades metafísicas, cuyo objetivo final es relacionarse con Dios. Nicolás de Cusa propone un método de la experiencia personal mediante una meditación ${ }^{44}$ perceptivo-intelectual que se efectúa mediante un icono de Dios, una imagen de Jesús que se grabó en el velo de Verónica ${ }^{45}$. En esta imagen la mirada del rostro representado es omnividente, es decir, independientemente del punto de vista ${ }^{46}$ que elija cada uno de los espectadores y independientemente de la cantidad de personas que observan a la imagen en el mismo tiempo, ésta los contempla con la misma intensidad ${ }^{47}$ :

43 DI, L. II, cap. 2. Para un análisis más detallado del tema de la metáfora del espejo en DI vease W. Haug, "Die Mauer des Paradieses. Zur mystica theologia des Nicolaus Cusanus in ,De visione De", Brechungen auf dem Weg zur Individualität. Kleine Schriften sur Literatur des Mittelalters, Tübingen, Niemeyer, 1997, p. 611; M. J. Soto-Bruna, La recomposición del espejo: análisis histórico-filosófico de la idea de expresión, Pamplona, Eunsa, 1995, pp. 147-187.

44 Sobre el papel de la meditación en el tratado véase $\mathrm{H}$. Simon, "Bildtheoretische Grundlagen des neuzeitlichen Bildes bei Nikolaus von Kues", Concilium medii aevi, 7, (2004), pp. 46-76.

45 Sobre la importancia de Velo de Verónica para el concepto de la representación en la filosofía y estética del Renacimiento, G. Wolf, Schleier und Spiegel. Traditionen des Christusbildes und die Bildconzepte der Renaissance, München, Wilhelm Fink, 2002.

46 Sobre el ángulo de la visión en el tratado cfr. Simon, "Bildtheoretische...", ob. cit. y M. de Certeau, "The Gaze of Nicholas of Cuse", Diacritics, 17 (1987), pp. 6-31.

47 Cfr. DVD, cap. XV, 65, p. 102. 
Cada uno de vosotros, desde cualquier lugar que lo mire, comprobará que el icono parece que le mira solamente a él ${ }^{48}$.

La elección del icono de Dios no es casual, pues quiere que el espectador se identifique con el Cristo sufriente que simboliza una conexión dialéctica entre el mundo divino y el mundo terrenal ${ }^{49}$.

Este tipo de la imagen votiva se vincula a la metáfora del espejo ${ }^{50}$. En La Visión de Dios esta relación entre el retrato y el espejo ${ }^{51}$ hace su presencia mediante la asociación de una imagen pintada de Cristo con el espejo como reflejo de una vida eterna. A continuación De Cusa desarrolla esta analogía, donde el rostro de Cristo, presentado como la imagen verdadera de Dios se asocia con el espejo vivo en el que todo reluce y que da forma a todo ${ }^{52}$. La mirada de los ojos pintados se convierte así en una ventana a través de la cual el hombre puede acceder a otra realidad $^{53}$, puede contemplar el paraíso mismo ${ }^{54}$.

La mirada del icono conecta dos niveles de la realidad, donde, a pesar de una total diferencia, se cruzan y coinciden el ojo humano y el ojo omnivedente de Dios en la percepción de la infinitud. $Y$ a pesar de toda la insignificancia de esta visión individual, en su insimilitud con la proyección de la mirada divina, el hombre ve

48 Ibídem, Prólogo, 3, p. 62.

49 Cfr. C. L. Miller, Reading Cusanus: Metaphor and Dialectic in a Conjectural Universe, Washington, D.C., Catholic University of America Press, 2003. p.150; A. Stock, "Die Rolle der 'Icona Dei' in der Spekulation De visione Dei", MFCG, 18 (1989), pp. 50-62. Este punto de vista es debatido por N. Herold, "Bild der Wahrheit-Wahrheit des Bildes: Zur Deutung des Blicks aus dem Bild in der Cusanische Schrift De Visione Dei", en V. Gerhardt y N. Herold (eds.), Wahrheit und Begründung, Würzburg, Königshausen und Neumann, 1985, pp. 71-98.

50 Cfr. Wolf, Schleier..., ob. cit., pp., 213-243.

51 Sobre la asociación entre el retrato y el espejo véase el artículo de S. Tritz, "Ad imaginem et similitudinem: Bildtheologie, Malertheorie ynd Kunstpraxis zur Zeit des Nikolaus von Kues", en I. Bocken y H. Shwaetzer (eds.), Spiegel und Porträt : zur Bedeutung zweier zentraler Bilder im Denken des Nicolaus Cusanus: Festgabe für Klaus Reinhardt zum 70. Geburtstag, Maastricht, Shaker, 2005, pp. 159-177.

52 Cfr. DVD, cap. XII, 49, p. 92, h49; cap. XV, 67, pp. 103-104.

53 Esta concepción tiene su paralelo en la teoría de Alberti sobre la necesidad de presencia en una historia de un rostro que llama la atención (Alberti, El tratado de la pintura...,ob. cit, L. II, p. 240). Leonardo da Vinci postula el ojo como la ventana del alma (Leonardo da Vinci, Tratado de pintura, A. González García (ed.), Madrid, Akal, 1986, p.51). Esta idea aparecerá más tarde en L. Dolce que va a subrayar el papel de los ojos como espejos del alma que deben influir al espectador. Cfr. A. Neumeyer, Der Blick aus dem Bilde, Berlin,Gebr. Mann, 1964, p.53.

54 Cfr. DVD, cap. III, 13, p.69. en el ojo de Dios tanto lo trascendental y lo inmanente, como su propia mirada:

Todo rostro que puede mirar tu rostro, no ve otra, cosa o algo diverso de sí mismo, porque ve su propia verdad ${ }^{55}$.

Así, como el ojo, por muy pequeño que sea, puede acoger dentro de sí figurativamente una gran montaña, la criatura de Dios mirándose en Dios se ve a sí misma como el reflejo de su poder y grandeza, percibe en sí la fuerza creativa de $\operatorname{Dios}^{56}$.

En el círculo de las metáforas que propone $\mathrm{Ni}$ colás de Cusa como punto de partida para un ejercicio metafísico junto al icono de Cristo, hacen su presencia otras representaciones de distinta temática y localización: un autorretrato de Rogier van der Weyden que se encontraba en el Ayuntamiento de Bruselas, el arquero, ubicado en el mercado de Nuremberg, el ángel que decoraba el castillo de Brixen ${ }^{57}$. Estas imágenes desempeñan el papel de los espejos que reflejan las sucesivas apariencias de la mirada. El espacio que organiza esta mirada omnividente posee una profundidad y está construido a partir de unas experiencias visuales variadas que entrelazan uno con el otro, constituyendo un teatro de las imágenes mentales de carácter polifocal. La relación entre el espectador y la imagen se establece mediante un diálogo, donde actúan el poder de la imagen y el esfuerzo perceptivo-intelectual del espectador. Por otro lado, el tratado tiene una doble estructura, compuesta del texto y de la imagen. La presencia de estos dos niveles en el tratado presupone un esfuerzo doble por parte del espectador que mediante una práctica racional, intelectual y otra, contemplativa, puede llegar a una visión superior.

La metáfora de la visión como el paradigma del proceso cognitivo esclarece la idea de que cada hombre puede conocer a Dios mediante su propio esfuerzo y la utilización de su

55 Ibídem, cap.VI, 19, p. 73.

56 Ibídem, cap. VII, 32, p. 81.

57 Sobre las imágenes que cita De Cusa en su tratado, véase, Herold, "Bild der Wahrheit...", ob. cit., pp. 73-76. 
perspectiva individual. Aquí el espíritu humano recibe un papel activo en el proceso de asimilación con el ejemplar.

El arte del retrato o autorretrato aparece en los Diálogos del Idiota sobre la mente como metáfora de la mente activa y productiva ${ }^{58}$. El laico propone que Dios está relacionado con la mente humana en la misma medida en la que el pintor lo está a su autorretrato, de manera que las mentes humanas son revelaciones de la mente creativa de Dios:

Sabes ya que nuestra mente es una cierta potencia que posee la imagen del arte divino a la que se aludió ya. Por ello, las cosas que de modo muy verdadero son propios del arte absoluto, pertenecen también de modo verdadero a nuestra mente, que es su imagen. La mente ha sido creada por el arte creador como si éste quisiera crearse a sí mismo, pero puesto que el arte infinito no es multiplicable, lo que surge es una imagen suya, lo mismo que si un pintor quisiera pintarse a sí mismo, pero al no ser él multiplicable, pintándose a sí mismo hace surgir una imagen suya ${ }^{59}$.

Nicolás de Cusa desarrolla una compleja teoría de la mímesis mediante la introducción del concepto de la similitud visto a través de la contraposición de las categorías vivo/muerto. Así De Cusa propone que para el pintor que quiere realizar su autorretrato caben dos posibilidades. Y, dependiendo de la vía que elija el pintor, dependen los resultados de su actividad. Así, se puede hacer una imagen que reproduzca con más similitud las características externas, pero permanece estática, pasiva en su ser, o realizar una imagen que aunque parezca menos similar en su expresión es más viva, es decir, dinámica o activa:

Lo mismo que si un pintor hiciese dos imágenes, de las cuales, una imagen muerta pareciese más semejante a él en acto, y otra menos semejante pero en cambio viva, es decir, tal que estimulada por su objeto a moverse, fuese

58 Para el análisis de las concepciones estéticas con referencia a este escrito puede consultarse Simon, "Bildtheoretische...", ob. cit. y Wolf, Schleier...,ob. cit., pp. 260-262.

59 DM, cap. XIII, pp. 109-110. capaz de hacerse cada vez más conforme a él, nadie dudaría que la segunda es más perfecta en cuanto imita más el arte de pintor ${ }^{60}$.

Por tanto, podemos ver que Nicolás da primacía a un autorretrato vivo, dinámico que es capaz de hacerse cada vez más similar a su ejemplar mediante su propia actividad, un movimiento espiritual ${ }^{61}$ incluso cuando el original permanece finalmente inaccesible. Esta capacidad de asemejarse a Dios se refiere en esta metáfora no al espectador, sino a una imagen pictórica que se postula como una obra de arte abierta, capaz de actuar e influir en el que la contempla. Aquí tenemos una reflexión sobre el problema de la representación en cuanto a su poder para conmover el espíritu del espectador. Está claro que esta reflexión tiene un carácter secundario y sirve como punto de partida para unas especulaciones filosóficas. Sin embargo, me planteo una pregunta: ¿No será posible que la visión estético-metafísica que tiene El Cusano sobre el poder de la imagen parta de su experiencia personal ante una representación pictórica y pueda ser relacionada con el concepto de la istoria que plantea Alberti sobre la necesidad de conmover al espectador? ${ }^{62}$

Con la metáfora del autorretrato que utiliza De Cusa se refuerza la noción ontológica del hombre: el mismo Dios se convierte en el hombre con la participación del Espíritu y el acto creativo $^{63}$.

Así, vemos, que junto a las metáforas de la imagen del espejo y del retrato o autorretrato pictórico en la esfera de la especulación filosófica o en la mirada reflectiva de la filosofía penetra la creatividad artística y sus resultados.

En el tratado El Berilo, De Cusa utiliza el concepto del espejo para afirmar que el hombre es el segundo Dios. El punto de partida aquí es una piedra brillante, blanca y transpa-

60 Ibídem, p.110.

61 Cfr. Simon, "Bildtheoretische...", ob. cit., pp. 70-75.

62 Alberti, El tratado de la pintura..., ob. cit., p. 238.

63 Sobre el movimiento del espíritu humano mediante el cual éste se equipara a Dios, véase Simon, "Bildtheoretische...", ob. cit., pp. 46-76. 
rente que tiene una forma cóncava y convexa a la vez denominada berilo ${ }^{64}$. La naturaleza de esta piedra transparente es tal que permite refractar la visión del que mira a través de él en las miríadas de las superficies y las formas. La visión sensible aquí constituye un paso hacia la visión intelectual, de tal manera que el berilo se transforma mediante un prisma mental en el medio de la reflexión metafísica. Dicha noción se desarolla aquí a partir de una complicada metáfora del espejo-juego que constituye un método para obtener la imagen de lo trascendental. El mecanismo de este espejo se articula mediante un doble movimiento. El primero consiste en un profundo proceso de autoconocimiento que permite reconocer a sí mismo como la imagen del Creador infinito ${ }^{65}$, a este paso le sigue un reflexivo camino de profundización del autoconocimiento que permite entender que la mente y sus creaciones son la finita imagen de un arte infinito $^{66}$. Este entendimiento, ayudado por los medios de las lentes intelectuales, hace posible, a su vez, un avance hacia el segundo movimiento del espejo, donde la imagen que reconoce su condición de ser imagen, es capaz de ser consciente de sí mismo como la imagen de algo diferente que no puede ser visto cara a cara, sino que solo se hace visible invisiblemente a través de una indefinida profundización en su propio reflejo ${ }^{67}$.

El proceso de este conocimiento que va profundizándose cada vez más es llamado por Nicolás de Cusa la ciencia enigmática y es lo que pretende explicarse en el tratado mediante la metáfora de un espejo mental. Así la metáfora del espejo se utiliza aquí para enfatizar la naturaleza creativa de la mente humana, demostrando cómo la visión intelectual y la visión perceptual se entrelazan, permitiendo llegar a un grado más profundo del conocimiento mediante la observación y la intuición. Las

$64 D B, 3$, p.20.

65 Ibídem, 9, p. 22.

66 Cfr. C.Rusconi, "The nature of mirror in the light of the scientia aénigmatica in De Beryllo", en Bocken y Shwaetzer (eds.), Spiegel..., ob. cit., p.100; véase también K.-H.Volkmann-Schluck, Nicolò Cusano: la filosofia nel trapasso del Medioevo all'Età Moderna, traducción al italiano de U. Proch, Brescia, Morcelliana, 1993, parte III, cap.2, pp. 127-139.

67 Cfr. DB, cap.7, p. 21. experiencias sensible e intelectual poseen una naturaleza esencialmente activa, expresiva y subjetiva que permite al hombre revelar su ser creativo y llegar a ser de esta manera la similitud del poder productivo de Dios.

\section{La imagen y el espejo en el espectro de la luz renacentista}

En el contexto de las reflexiones sobre la imagen y el espejo en El Cusano sería interesante ver la transformación que sufre la imagen en el tránsito del medievo a la época moderna que empieza con el Renacimiento. Es el tiempo del nacimiento del cuadro. La imagen pictórica deja al lado su función exclusivamente icónica, al transformarse en un cuadro, ésta se convierte en el objeto del esfuerzo del intelecto conscientemente dirigido, sirve como punto de partida para la contemplación activa y reflexión metafísica. La imagen pictórica ya no tiene un carácter monosemántico, sino que integra distintos niveles de la realidad, desempeñando el papel de un tratado filosófico y teológico, de una obra poética, o de un ejercicio metafísico. El enriquecimiento de las percepciones individuales reflejan también distintos niveles de la conciencia humana. El arte renacentista se distingue por la tendencia a la difuminación entre lo que acontece realmente y lo que trasciende los límites de las posibilidades del hombre. Este proceso de la mentalización de la imagen viene acompañado por una serie de cambios estructurales. En primer lugar, la aparición del bastidor ${ }^{68}$ que va a funcionar como la ventana o puerta de salida espacial al otro mundo que existe al otro lado del espectador o el acceso al mundo de la visión intelectual.

Una multiplicación de los sentidos y los niveles de la realidad en el retablo puede percibirse por la coexistencia en el mismo de partículas pintadas en distintos colores y aquellas que se realizan con la técnica de grisallas. La presencia de estas últimas, contrastando con el resto del ambiente pictórico puede significar

68 Cfr. C. Eisler, "Review of S. Ringdom, Icon to Narrative", Art Bulletin, 1 (1969), pp. 186-188, esp. p.187. 
una visión, una realidad suprema ${ }^{69}$. El pintor se propone demostrar una visión hecha realidad, mediante la alternancia de las artes. Así, si nos fijamos en La Virgen en una Iglesia de Jan van Eyck (Fig.1), vemos que en el nicho aparece la Virgen con el Niño flanqueada por dos velas. Puede verse cómo esta pequeña Virgen concebida como la imitación de la escultura ${ }^{70}$ es muy parecida a la figura grande que aparece en primer término. La conexión conceptual de estas dos imágenes de la Virgen se acentúa mediante los efectos lumínicos. Como apunta Harbison, "no es accidental que haya solo dos focos de la luz que proyecten las velas, lo cual nos lleva a la conclusión de que la imagen de la Virgen en color puede ser una versión de la estatua fría hecha realidad"71. Efectivamente, parece que la estatua renace ante los ojos del espectador y entra con toda su belleza deslumbrante al espacio sagrado de la iglesia. La imagen realizada por Van Eyck funciona como el espejo que graba para siempre en su superficie refractaria la visión personal concebida en el acto de la práctica meditativa individual.

Otro nivel de la representación pictórica es el cuadro dentro del cuadro ${ }^{72}$ que materializa una gradación de niveles de la percepción, con una transparencia cristalina, como si tratase de una explicación de la mente efectuada a través del conocimiento y la meditación que viene reflejada en la galería de las imágenes intelectuales, en el teatro de la memoria de la conciencia humana. Por ejemplo, en el Libro de Horas de María de Borgoña ${ }^{73}$ en la miniatura

69 Para la cuestión de la técnica de las grisallas y los grados de realidad véase $P$. Philliport, "Les grisalles et les degrés de réalité de l'image dans la peinture flemande des XVe et XVIe siécles",Bulletin des Musées Royaux des Beaux-Arts de Belgique, 15(1966), pp. 225-242.

70 La alternancia en la obra pictórica de imágenes realizadas en color y aquellas realizadas con la técnica de grisalla se corresponde con el fenómeno del paragone, en italiano "comparación", debate del Renacimiento italiano acerca de qué forma de arte es superior a las otras, Leonardo da Vinci en su Tratado de la pintura defiende la superioridad de la pintura sobre la escultura. Sobre este tema, véase K. B. Lepper, Der "Paragone". Studien zu den Bewerungsnormen der Bildenden Künste mi frühen Humanismus (1350-1480), Bonn, K.B. Lepper, 1987.

71 C. Harbison, "Miracles Happen: Image and Experience in Jan Van Eycks Madonna in a Church", en B. Cassidy (ed.), Iconography at the Crossroads, Princeton, Princeton University, 1993 pp. 157-166, esp. p. 160.

72 Sobre la temática de cuadro dentro de cuadro véase J. Gállego, El cuadro dentro del cuadro, Madrid, Cátedra, 1978.

73 Cfr. A. Grebe, "Die Fensterbilder des sogenannten Meisters der Maria von Burgund", en Ch. Kruse y F.Thürlemann (eds.), Porträt - Land-
María de Borgoña en oración (Fig.2) vemos a la gran duquesa leyendo el Libro de Horas junto a la ventana, mientras que en la ventana aparece su visión -la escena de la adoración de la Virgen en la iglesia. El acontecimiento sagrado se convierte en el fruto de la meditación personal. Las apariencias exteriores, representadas con gran detalle, se difuminan transformándose en el pensamiento piadoso.

La función del cuadro dentro del cuadro también puede desempeñar el motivo del espejo con su compleja metamorfología que complica, multiplica la realidad, hablando en términos cusanos $^{74}$.

Por último, nos centraremos en la perspectiva, el concepto teorético fundamental del Renacimiento $\mathrm{O}^{75}$. La perspectiva viene de la palabra latina perspicere y significa ver. La perspectiva encarna, sobre todo, una visión creativa, activa, que expresa la penetración de la visión intelectual desde el mundo empírico al mundo respresentado, a otra realidad ${ }^{76}$. Así lo señala explícitamente el contemporáneo de Nicolás de Cusa, Luca Pacioli: "Si dicen que la música contenta al oído, que es uno de los sentidos naturales, también la perspectiva contenta la vista, la cual tanto es más digna cuanto que es la primera puerta del intelecto" ${ }^{\prime 77}$.

En el Quattrocento se desarrolla una teoría de la perspectiva que pretende poner el arte de

schaft - Interieur Literatur und Anthropologie, Gunter Narr Verlag, 1999, pp. 257-271.

74 Sobre el significado simbólico del espejo véase H. Schwarz, "The Mirror in Art", Art Quarterly, 15 (1952), pp. 97-118 y G. Hartlaub, Die Zauber des Spiegels. Geschichte und Bedeutung des Spegels in der Kunst, München, R. Piper, 1951. Para el tema del espejo y los efectos espaciales: J. Bialostocki, "Man and Mirror in Painting: Reality and Transience", en I. Lavin y J.Plummer (eds.), Studies in Late Medieval and Renaissance Painting in Honor of Millard Meis, New York, New York University Press, 1977, pp. 61-72.

75 Una breve historia de la teoría de la perspectiva en el Renacimiento y de los métodos interpretativos de este problema puede encontrarse en M. Riedenauer, "Spielraum der Welt: Perspectivität im Quattrocento", en R. Esterbauer y G. Pöltner (eds.), Orte des Schönen: phänomenologische Annäherungen: für Günther Pöltner zum 60. Geburtstag, Wien, Königshausen und Neumann, 2003, pp. 351-379. Sobre la posible influencia de Nicolás de Cusa en los artistas e intelectuales renacentistas, véase D. Koenigsberger, Renaissance Man and Creative Thinking: a History of Concepts of Harmony, 1400-1700, Sussex, Harvester Press, 1979.

76 Neumeyer, Der Blick...,ob. cit., pp. 40-42.

77 L. Pacioli, La divina proporción, traducción de R. Resta, Buenos Aires, Losada, 1959, parte I, cap. III, p. 67. 
la pintura sobre una base científica, vinculándola a la geometría y la óptica y de esta manera lograr una elevación del estatuto de la misma ${ }^{78}$. Así, Alberti en su tratado Della Pittura define la imagen como una intersección vertical y cristalina que se proyecta a través de una pirámide visual $^{79}$. La metáfora del espejo aparece en el análisis de Alberti con dos funciones, práctica y metafórica. La primera se desarrolla en el apartado que está dedicado al problema del dibujo, donde se asocia el espejo con el velo ${ }^{80}$, tela transparente que se coloca entre el objeto que debe representarse y la vista del pintor. El empleo del concepto del espejo en su función metafórica se realiza mediante la analogía de la invención de la pintura con el mito de Narciso. La superficie refractaria del agua, que funciona como el espejo natural, se concibe como la metáfora de la imitación de la naturaleza y la belleza sensitiva ${ }^{81}$ :

Por lo cual muchas veces he dicho en presencia de algunos amigos que el inventor de la pintura fue sin duda aquel joven Narciso que fue convertido en flor: porque siendo la pintura como la flor de todas las artes, parece que se puede acomodar sin violencia la fábula de Narciso a ella: porque ¿qué otra cosa es pintar que tomar el auxilio del arte la superficie de la fuente? ${ }^{82}$

De ahí que la pintura adquiere en la concepción de Alberti, por un lado, un valor estético y, por otro, se le dota de un carácter intelectual, puesto que el espejo se asocia al acto reflexivo de autoconocimiento ${ }^{83}$.

Para tener una visión más completa tenemos que detenernos en la experiencia perceptiva

78 Cfr. Baxandal, Painting..., ob. cit., pp.103-109.

79 Alberti, El tratado de la pintura..., ob. cit., L. II, p. 227.

80 Wolf asocia el concepto de velo que utiliza Alberti con la idea del velo de Verónica utilizada por Nicolás de Cusa en DVD. Cfr. G. Wolf, "De icona sive de visione Dei, cap. XXV", en Preimesberger, Porträt..., ob. cit., p. 205.

81 Sobre la interpretación del mito de Narciso en el tratado de Alberti, véase U. Pfisterer, "Künstlerliebe. Der Narcissus-Mythos bei Leon Battista Alberti und die Aristoteles-Lektüre der Frühereaissance", Zeitschrift für Kunstgeschichte, 64 (2001), pp.305-330. Sobre el mito de Narciso y el concepto de mímesis, véase N. Suthor, "Ovidus Naso: Der Irrtum des Narziss (vor 8 n. Chr.)", en Preimesberger, Porträt..., ob. cit., pp. 96-111.

82 Alberti, El tratado de la pintura..., ob. cit., pp. 221-222.

83 Sobre la historia filosófica y estética del concepto del espejo, véase S. Melchior-Bonnet, Histoire du Miroir, Paris, Imago, 1994. de la época del Renacimiento. Nos centraremos en la oda en la que Lucas de Heere, poeta, humanista y pintor flamenco del siglo XVI, elogia el Retablo de Gante de Jan van Eyck (Fig.3). La primera parte del encomio de Lucas de Heere ${ }^{84}$ hace hincapié en la fuerza de Jan van Eyck para vivificar las imágenes mediante los reflejos de la luz y la técnica de color propia del artista, es decir, lo que se elogia no es la reproducción exacta de los objetos del mundo real sino la capacidad para hacer imágenes que están vivas, similitudes del intelecto del artista. La metáfora que se utiliza para explicar la percepción visual que uno experimenta ante el Retablo, reside en que cada objeto y cada personaje representado en la composición parece estar vivo y a punto de salir del cuadro: es el espejo. El espejo se concibe aquí como una imagen viva que multiplica los distintos niveles de la realidad, integrando en su luz refractaria a todo el mundo.

La suplantación del icono por el cuadro forma parte de un proceso gradual de ideificación o mentalización de la nueva cultura con el intelecto como una metáfora central de la fuerza creativa del hombre. Este último, mediante su acto productivo, se convierte en la imagen viva, en la similitud de Dios. La imagen se concibe como un espejo vivo que integra, igual que en El Berilo de Nicolás de Cusa, distintos niveles de la realidad, donde tiene lugar la coincidencia de los opuestos. En conclusión, esta transformación cultural que sucede en el Renacimiento tiene como su representante clave a Nicolás de Cusa, cuyo pensamiento filosófico y estético refleja de manera explícita las tendencias culturales de la época, tanto a nivel prácti$\mathrm{co}$, como teórico.

\section{Bibliografía}

\footnotetext{
1. Alberti, L. B. y Da Vinci, L., El tratado de la pintura y los tres libros que sobre el mismo arte escribió León Bautista Alberti, traducción de

84 “(...) Pero es una cosa vana elogiar algo, sobre todo allí donde cada cosa representa la más rica y preciosa piedra, pues parece que todo está aquí como si fuera vivo y saliera del cuadro. Son espejos, sí, espejos y no cuadros, en absoluto (...)". Aparece citado en K. van Mander, Het Schilder-boeck, [La vida de los pintores Jan y Hubert Van Eyck], traducción al ruso de V. Minorsky, San Petesburgo, Azbooka, 2007, p.45.
} 
D. A. Rejón de Silva, Valencia, Librerías París-Valencia, 1989.

2. Alvarez-Gómez, M., "Adecuación e identidad. Sobre la idea de verdad en Santo Tomás y Nicolás de Cusa", Anales de la cátedra Francisco Suárez, 4 (1964), pp.5-52.

3. André, J. M., “La dimensión simbólica del arte en Nicolás de Cusa", Anuario filosófico, 28 (1995), pp. 547- 582.

4. Batkin, L., Leonardo da Vinci y las particularidades del pensamiento artístico en el Renacimiento, Moscú, Iskusstvo, 1990.

5. M., Painting and Experience in Fifteenth Century Italy: a Primer in the Social History of Pictorial Style, Oxford, Oxford University Press,1988.

6. Betrán, R., Leon Battista Alberti y la teoría de la creación artística en el Renacimiento, Zaragoza, Delegación en Zaragoza del Colegio Oficial de Arquitectos de Aragón, 1992.

7. Bialostocki, J., "Man and Mirror in Painting: Reality and Transience", en I. Lavin and J. Plummer (ed.), Studies in Late Medieval and Renaissance Painting in Honor of Millard Meiss, New York, New York University Press, 1977, pp. 61-72.

8. Cassirer, E., Individuo y cosmos en la filosofía del Renacimiento, traducción de A. Bixio, Buenos Aires, Emecé, 1951.

9. Certeau, M. de, “The Gaze of Nicholas of Cuse", Diacritics, 17 (1987), pp. 2-38.

10. Eisler, C., "Review of S. Ringdom, Icon to Narrative", Art Bulletin, 1 (1969), pp. 186-188.

11. Flasch, K., “Nikolaus von Kues und Pico della Mirandola", MFCG, 14 (1980), pp. 113-120.

12. Gállego, J., El cuadro dentro del cuadro, Madrid, Cátedra, 1978.
13. Gamberoni, P., "Cusanus und der italienische Humanismus", Bijdragen-Tijdschrift voor Filosofie en Theologie, (25), 1964, pp. 398-41.

14. González, Á. L., “Introducción”, en Nicolás de Cusa, El Berilo, introducción, traducción y notas de Á. L. González, Cuadernos de Anuario Filosófico № 200, Pamplona, Sevicio de Publicaciones de la Universidad de Navarra, 2007, pp. 5-17.

15. Gosebruch, M., "Varieta bei Leon Battista Alberti und der wissenschaftliche Renaissancebegriff", en Zeitschrift für Kunstgeschichte, Bd 20, Heft3 (1957), pp. 229-238.

16. Grebe, A., “Die Fensterbilder des sogenannten Meisters der Maria von Burgund", en Ch. Kruse y F.Thürlemann (eds.), PorträtLandschaft-Interieur Literatur und Anthropologie, Tübingen, Gunter Narr Verlag, 1999, pp. 257-271.

17. Harbison, C., “Miracles Happen: Image and Experience in Jan Van Eycks Madonna in a Church", en B. Cassidy (ed.), Iconography at the Crossroads, Princeton, Princeton University Press, 1993, pp.157-166.

18. Hartlaub, G., Die Zauber des Spiegels. Geschichte und Bedeutung des Spegels in der Kunst, München, R. Piper, 1951.

19. Haug, W., “Die Mauer des Paradieses. Zur mystica theologia des Nicolaus Cusanus in 'De visione Dei'"', en Brechungen auf dem Weg zur Individualität. Kleine Schriften sur Literatur des Mittelalters, Tübingen, Niemeyer, 1997, pp. 606-616.

20. Hempel, E., Nikolaus von Kues in seinen Beziehungen zur bildenden Kunst, Berlin, Akademie-Verlag,1953.

21. Herold, N., "Bild der Wahrheit-Wahrheit des Bildes: Zur Deutung des Blicks aus dem Bild in der Cusanische Schrift De Visione Dei", en V. Gerhardt y N. Herold 
(eds.), Wahrheit und Begründung , Würzburg, Königshausen und Neumann, 1985, pp. 71-98.

22. Jansen, D., Similitudo. Untersuchungen zur den Bildnissen Jan van Eycks, Reihe: Dissertationen zur Kunstgeschichte 28, KölnWien, 1988.

23. Koenigsberger, D., Renaissance Man and Creative Thinking: a History of Concepts of Harmony, 1400-1700, Sussex, Harvester Press, 1979.

24. Kristeller, P., "Humanismus", en Ch. B. Schmitt, Q. Skinner, E. Kessler and J, Kraye (ed.), The Cambrige History of Renaissance Philosophy, Cambridge, Cambridge University Press,1988, pp.111-137.

25. Landino, C., Scritti critici e teorici, R. Cardini (ed.), vol. 1., Roma, Bulzoni, 1974.

26. Lee, R. W., Ut pictura poesis: La teoría humanística de la pintura, traducción de C. Luca de Tena, Madrid, Cátedra, 1982.

27. Manetti, G., “De dignitate et excelentia hominis", en E. Garin (ed.), Prosatori latini de Quattrocento, Milano, R. Ricciardi, 1952.

28. Leonardo da Vinci, Tratado de pintura, A. González García (ed.), Madrid, Akal, 1986.

29. Lepper, K. B., Der "Paragone". Studien zu den Bewerungsnormen der Bildenden Künste mi frühen Humanismus (1350-1480), Bonn, K.B. Lepper, 1987.

30. Mander, K. van, Het Schilder-boeck, [La vida de los pintores Jan y Hubert Van Eyck], traducción al ruso de V. Minorsky, San Petesburgo, Azbooka, 2007.

31. Melchior-Bonnet, S., Histoire du Miroir, Paris, Imago, 1994.

32. Miller, C. L., Reading Cusanus: Metaphor and Dialectic in a Conjectural Universe, Washing- ton, D.C., Catholic University of America Press, 2003.

33. Neumeyer, A., Der Blick aus dem Bilde, Berlin, Gebr. Mann, 1964.

34. Nicolás de Cusa, El Berilo, Introducción, traducción y notas de Á. L. González, Cuadernos de Anuario Filosófico № 200, Pamplona, Servicio de Publicaciones de la Universidad de Navarra, 2007. (Abreviatura en el texto: DB).

35. Nicolás de Cusa, De Coniecturis, en J. Hopkins (ed.), Nicholas of Cusa: Metaphysical Speculations, Volume Two, Minneapolis, Minnesota, Arthur J. Banning Press 2000. (Abreviatura en el texto: DC)

36. Nicolás de Cusa, La Docta Ignorancia, Traducción del latín, prólogo y notas de $\mathrm{M}$. Fuentes Benot, Buenos Aires-MadridMéxico, Aguilar, 1962. (Abreviatura en el texto: DI)

37. Nicolás de Cusa, La visión de Dios, Introducción y traducción de Á. L. González, Pamplona, Eunsa, 1994. (Abreviatura en el texto: DVD)

38. Nicolás de Cusa, "Idiota de la mente", en Diálogos del Idiota, Introducción y traducción de Á. L. González, Cuadernos de Anuario Filosófico № 64, Pamplona, Servicio de Publicaciones de la Universidad de Navarra, 1998. (Abreviatura en el texto: IM)

39. Nicolás de Cusa, De Ludo Globi, en J. Hopkins (ed.), Nicholas of Cusa: Metaphysical Speculations, Volume Two, Minneapolis, Minnesota, Arthur J. Banning Press, 2000. (Abreviatura en el texto: LG)

40. Nicolás de Cusa, Compendium, en Nicolás de Cusa, Obra completa, vol. 2, Moscú, Legado filosófico, 1979. (Abreviatura en el texto: Comp.)

41. Pacioli, L., La divina proporción, traducción de R. Resta, Buenos Aires, Losada, 1959. 
42. Panofsky, E., Idea. Contribución a la historia de la teoría del arte, traducción de M. T. Pumarega, Madrid, Cátedra, 1977.

43. Philliport, P., "Les grisalles et les degrés de réalité de l'image dans la peinture flemande des XVe et XVIe siécles",Bulletin des Musées Royaux des Beaux-Arts de Belgique, 15(1966), pp. 225-242.

44. Pfisterer, U., "Künstlerliebe. Der Narcissus-Mythos bei Leon Battista Alberti und die Aristoteles-Lektüre der Früherenaissance", Zeitschrift für Kunstgeschichte, 64 (2001), pp. 305-330.

45. Pochat, G., Historia de la estética y la teoría del arte, traducción de J. Chamorro Mielke, Madrid, Akal, 2008.

46. Preimesberger, R., “Der Verfasser der Priesterschrift: ... nach unserem Bild, uns ähnlich (6 Jhdt.v. Chr.)", en R. Preimesberger y otros (eds.), Porträt (Geschichte der klassischen Bildgattungen in Quellentexten und Kommentaren, 2), Berlin, Reimer,1999, pp.70-75.

47. Preimesberger, R., “Caius Secundus d. Ä.: Ähnlichkeit (77n.Chr.)”, en R. Preimesberger y otros (eds.) Porträt (Geschichte der klassischen Bildgattungen in Quellentexten und Kommentaren, 2), Berlin, Reimer, 1999, pp. 127-133.

48. Riedenauer, M., "Spielraum der Welt: Perspectivität im Quattrocento", en R. Esterbauer, y G. Pöltner (eds.), Orte des Schönen: phänomenologische Annäherungen : für Günther Pöltner zum 60. Geburtstag, Würzburg, Königshausen und Neumann, 2003, pp. 351-379.

49. Rusconi, C., "The nature of mirror in the light of the scientia aenigmatica in De Bery$l l o^{\prime \prime}$, en I. Bocken y H. Schwaetzer (eds.), Spiegel und Porträt : zur Bedeutung zweier zentraler Bilder im Denken des Nicolaus Cusanus. Festgabe für Klaus Reinhardt zum 70.
Geburtstag, Maastricht, Shaker, 2005, pp. 95-113.

50. Sannazaro, I., La Arcadia, traducción de J. M. Mesanza, Madrid, Editora Nacional, 1982.

51. Santinello, G., Il pensiero di Nicolò Cusano nella sua prospettiva estetica, Padova, Liviana, 1958.

52. Santinello, G., "L'uomo 'ad imaginem et similitudinem' nel Cusano", Doctor Seraphicus, 37(1990), pp. 85-97.

53. Seidlmayer, M., "Nikolaus von Cues und der Humanismus", en J. Koch (ed.), Humanismus, Mystik und Kunst in der Welt des Mittelalters, Brill, Leiden-Koln, 1953, pp. 1-39.

54. Simon, H., "Bildtheoretische Grundlagen des neuzeitlichen Bildes bei Nikolaus von Kues", Concilium medii aevi, 7,(2004), pp. 45-76.

55. Sokolov, M., El misterio de la vecindad. Hacia la metamorfología del arte en el Renacimiento, Moscú, Progress, 1999.

56. Soto-Bruna, M. J., La recomposición del espejo: análisis histórico-filosófico de la idea de expresión, Pamplona, Eunsa, 1995.

57. Stechow, W., Northern Renaissance Art, 14001600: Sources and Documents, Evanston, Ill., Northwestern University Press, 1999.

58. Stock, A., “Die Rolle der 'Icona Dei' in der Spekulation De visione Dei", MFCG, 18 (1989), pp. 50-62.

59. Suthor, N., "Ovidus Naso: Der Irrtum des Narziss (vor 8 n. Chr.)", en R. Preimesberger y otros (eds.) Porträt (Geschichte der klassischen Bildgattungen in Quellentexten und Kommentaren, 2), Berlin, Reimer, 1999, pp. 96-111.

60. Schwaetzer, H., "Viva similitudo", en H. Schwaetzer (ed.), Nicolaus Cusanus: Pers- 
pectiven seiner Geistphilosophie, Regensburg, Roderer, 2003, pp. 79-95.

61. Schwarz, H.,"The mirror in art”, Art Quarterly, 15 (1952), pp.97-118.

62. Tatarkiewicz, W., Historia de la estética, (obra completa 3 vol.), traducción de D. Rurzyka, Madrid, Akal, 1991.

63. Tatarkiewicz, W., Historia de seis ideas: arte, belleza, forma, creatividad, mimesis, experiencia estética, traducción de F. Rodríguez Martín, Madrid, Alianza, 2008.

64. Tritz, S., "Ad imaginem et similitudinem: Bildtheologie, Malertheorie und Kunstpraxis zur Zeit des Nikolaus von Kues", en I. Bocken y H. Shwaetzer (eds.), Spiegel und Porträt : zur Bedeutung zweier zentraler
Bilder im Denken des Nicolaus Cusanus.: Festgabe für Klaus Reinhardt zum 70. Geburtstag, Maastricht, Shaker, 2005, pp. 159-177.

65. Volkmann-Schluck, K.-H., Nicolò Cusano: la filosofia nel trapasso del Medioevo all'Età Moderna, traducción al italiano de U. Proch, Brescia, Morcelliana, 1993.

66. Watts, P. M., "Renaissance Humanism", en P. M. Watts (ed.), Introducing Nicholas of Cusa: a Guide to a Renaissance Man, New York, Paulist Press, 2004, pp.169-205.

67. Wolf, G., Schleier und Spiegel. Traditionen des Christusbildes und die Bildconzepte der Renaissance, München, Wilhelm Fink, 2002.

68. Wölfflin, H., El arte clásico: una introducción al Renacimiento italiano, traducción de A. Dieterich, Madrid, Alianza, 1985.

\section{Figuras}

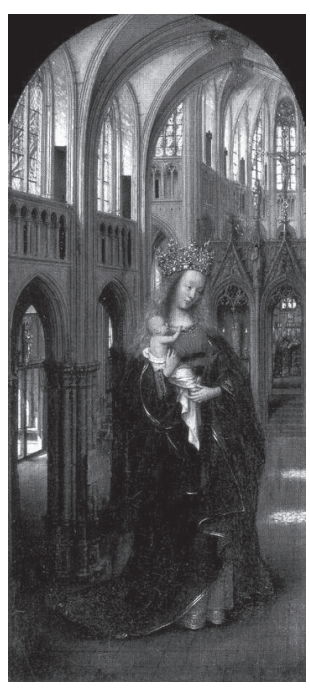

Fig.1: Jan van Eyck, $\mathrm{La}$ Virgen en una Iglesia (Staatliche Museen zu Berlin, Preussischer Kulturbesitz, Gemäldegalerie).

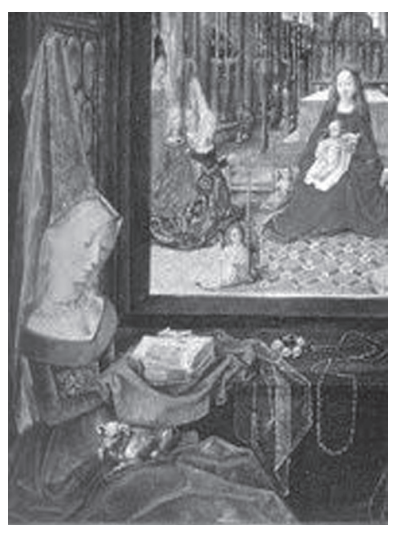

Fig.2: Maestro de María de Borgoña, miniatura María de Borgoña en oración del Libro de Horas de María de Borgoña (Österreichische Nationalbibliothek, Viena).

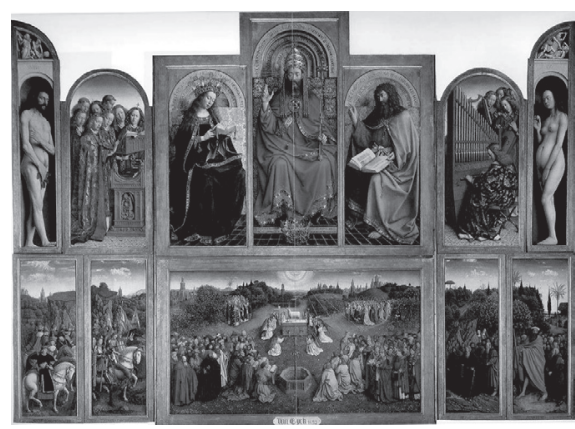

Fig.3: Jan Van Eyck, El Políptico de Gante (Iglesia de San Bavón, Gante). 